Ambiente \& Água - An Interdisciplinary Journal of Applied Science
ISSN 1980-993X - doi:10.4136/1980-993X
www.ambi-agua.net
E-mail: ambi-agua@agro.unitau.br

\title{
Hidrogeologia e hidroquímica dos aquíferos fraturados associados às rochas vulcânicas ácidas no Município de Carlos Barbosa (RS)
}

\author{
doi: 10.4136/ambi-agua.1270
}

Received: 01 Jan. 2014; Accepted: 09 Mar. 2014

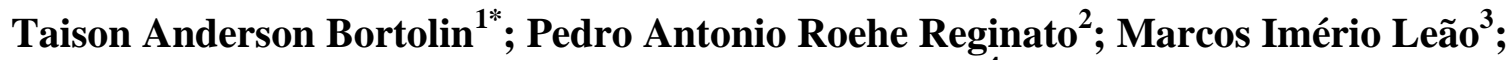 \\ Vania Elisabete Schneider ${ }^{4}$

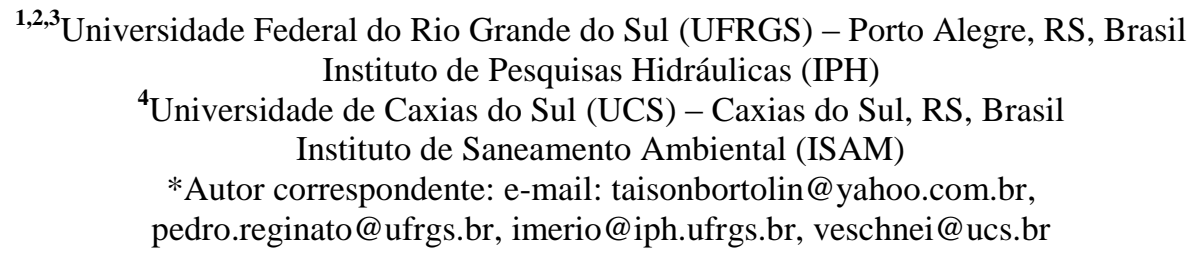

\section{RESUMO}

Este artigo apresenta o estudo hidrogeológico e hidroquímico dos aquíferos fraturados que formam o Sistema Aquífero Serra Geral (SASG) e que estão associados a rochas vulcânicas ácidas. A região de estudo compreende parte da área do município de Carlos Barbosa, localizado na região nordeste do estado do Rio Grande do Sul. O estudo foi desenvolvido a partir do inventário e cadastramento de poços tubulares existentes na região, do levantamento e interpretação de dados geológicos e hidrogeológicos, além da coleta e análise de amostras de água de poços tubulares que estão em funcionamento e são utilizados pela companhia de abastecimento CORSAN. Os resultados obtidos permitiram evidenciar que a maioria dos poços apresenta profundidade de até 150 metros com vazões médias que variam de 5 a $20 \mathrm{~m}^{3} \mathrm{~h}^{-1}$, localizados em zonas de média e alta densidade de fraturas, as quais possuem orientação preferencial para noroeste. Quanto à hidroquímica, as águas que circulam por esses aquíferos são do tipo bicarbonatadas cálcicas ou magnesianas, predominando as águas bicarbonatadas mistas e cálcicas, apresentando pequenas variações quanto à concentração dos íons e suas razões iônicas. Essas características hidroquímicas são típicas de águas que circulam por estruturas de rochas vulcânicas ácidas e indicam um baixo tempo de residência, sendo as concentrações variáveis com as profundidades das entradas da água.

Palavras-chave: caracterização hidrogeoquímica, sistema aquífero Serra Geral, águas subterrâneas.

\section{Hydrogeology and hydrochemistry of fractured aquifers associated with acidic volcanic rocks in the city of Carlos Barbosa (RS)}

\begin{abstract}
This paper presents the hydro-geological and hydro-chemical study of fractured aquifers that form the Serra Geral Aquifer System (SASG) associated with acid volcanic rocks. The study area comprises part of the city of Carlos Barbosa, located in the northeast region of Rio Grande do Sul State. The study was developed based on the inventory and registration of existing wells in the region, the survey and interpretation of geological and hydro-geological
\end{abstract}


data, in addition to the collection and analysis of samples from wells that are in operation and used by the CORSAN water supply company. The results highlighted that most wells have depth up to 150 meters with flow rates average ranging from 5 to $20 \mathrm{~m}^{3} \mathrm{~h}^{-1}$, located in areas with medium and high density of fractures, which have preferential orientation to the northwest. As for hydro-chemistry, water circulating through these aquifers is the calcic or magnesium bicarbonate type, predominantly mixed and calcic bicarbonate waters, with minor variations in the concentration of ions and their ionic reasons. These hydro-chemical characteristics are typical of waters that circulate within structures and acid volcanic rocks indicate a low residence, with concentrations varying with water input depths.

Keywords: hydro-geochemical characterization, Serra Geral aquifer system, groundwater.

\section{INTRODUÇÃO}

Na região nordeste do estado do Rio Grande do Sul, os recursos hídricos subterrâneos têm grande importância, pois na maioria das situações correspondem à principal fonte de água disponível para abastecimento humano ou uso no desenvolvimento de atividades industriais ou agrícolas.

Nessa região as águas subterrâneas estão associadas a dois tipos principais de aquíferos: o livre (freático) e o fraturado (Reginato, 2003). O primeiro aquífero fornece volumes reduzidos de água, sendo mais utilizado pela população rural, que capta suas águas através de poços escavados ou fontes. O segundo aquífero fornece maiores volumes e água com melhor qualidade, sendo utilizado para abastecimento da população urbana da maioria dos municípios, bem como de algumas comunidades rurais, através de poços tubulares comunitários.

Este sistema aquífero ocupa uma extensa área no nordeste do planalto rio-grandense, e está associado com as rochas vulcânicas ácidas e básicas que formam a Unidade Hidroestratigráfica Serra Geral. As litologias dessa unidade são representadas predominantemente por riolitos, riodacitos e, em menor proporção, basaltos fraturados. A capacidade específica é inferior a $0,5 \mathrm{~m} / \mathrm{h} / \mathrm{m}$, entretanto, excepcionalmente em áreas mais fraturadas ou com arenitos na base do sistema, podem ser encontrados valores superiores a $2 \mathrm{~m} 3 / \mathrm{h} / \mathrm{m}$ (Machado e Freitas, 2005).

As águas que circulam por esses aquíferos apresentam características hidroquímicas e qualidade variada. Essa diferenciação depende do tipo de aquífero, da litologia, da recarga, do grau de confinamento, da vulnerabilidade e do uso e ocupação do solo (Reginato, 2003; Reginato et al., 2012).

Este artigo objetiva apresentar o estudo hidrogeológico e hidroquímico das águas subterrâneas do Sistema Aquífero Serra Geral associado às rochas vulcânicas ácidas, na área abrangida pelo município de Carlos Barbosa, inserido na região nordeste do Estado do Rio Grande do Sul.

\section{2. ÁREA DE ESTUDO}

A área de estudo está localizada na região nordeste do Estado do Rio Grande do Sul, mais precisamente na zona urbana do município de Carlos Barbosa, inserida na região do planalto do estado, conforme apresenta o mapa da Figura 1. O município está localizado a $676 \mathrm{~m}$ acima do nível do mar, sendo a altitude da sede de $618 \mathrm{~m}$. Encontra-se entre as coordenadas geográficas $29^{\circ} 18^{\prime}$ de Latitude Sul e $51^{\circ} 30^{\prime}$ de Longitude Oeste, sendo abastecido em sua totalidade por águas subterrâneas. 


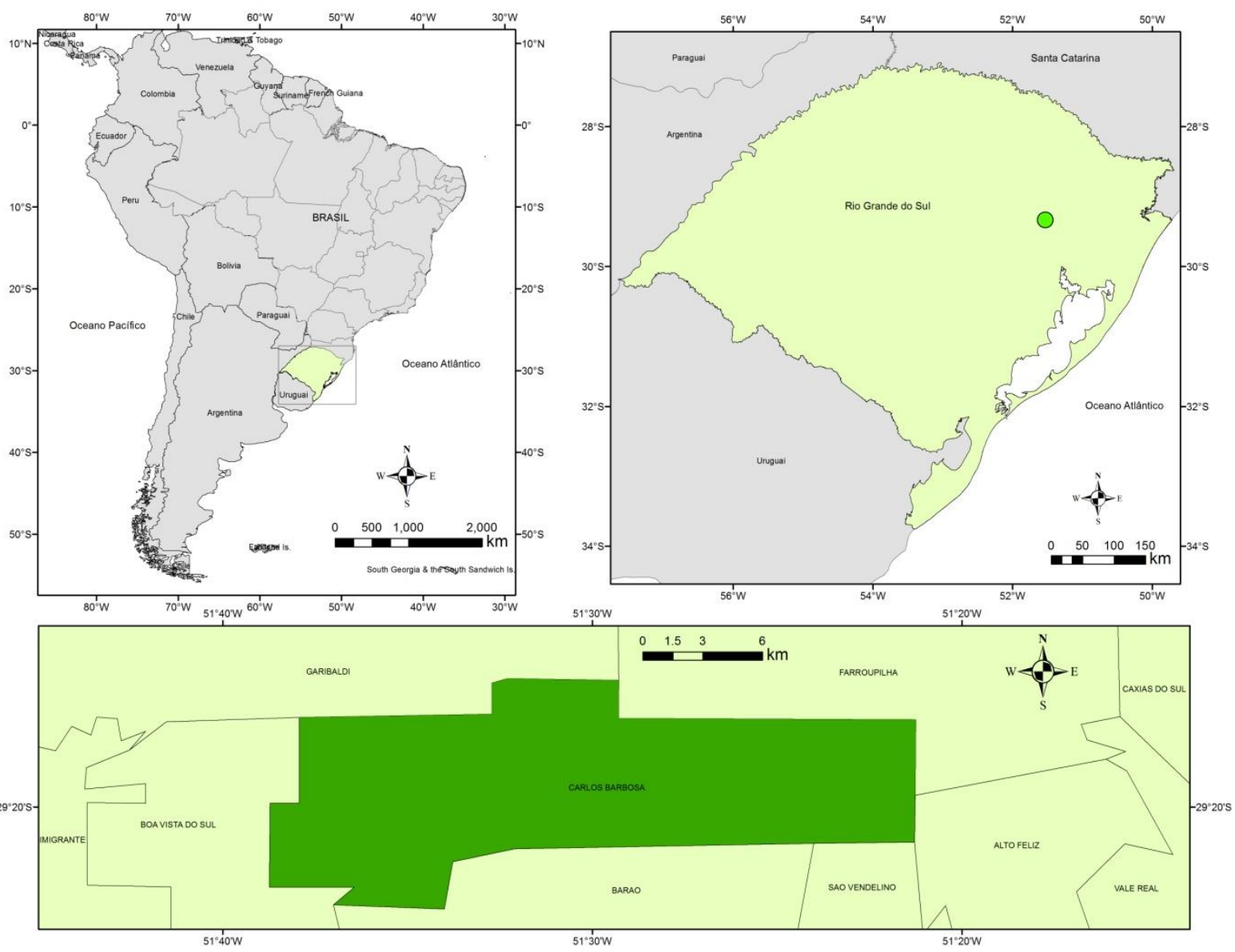

Figura 1. Localização da área de estudo.

\section{MATERIAL E MÉTODOS}

Para o desenvolvimento desse estudo foram realizados o inventário e cadastramento de poços tubulares existentes na região, o levantamento e interpretação de dados geológicos e hidrogeológicos, além da coleta e análise de amostras de água de poços tubulares.

O inventário e cadastramento dos poços tubulares foi realizado através da consulta ao Sistema de Informações de Águas Subterrâneas (SIAGAS-CPRM), à Companhia Riograndense de Abastecimento (CORSAN) e por meio de levantamentos de campo. Os dados geológicos e hidrogeológicos, tais como tipo de rocha e suas características, nível estático dos poços, nível dinâmico, parâmetros hidrodinâmicos (transmissividade e capacidade específica) e vazão, foram utilizados na elaboração de um banco de dados criado com uso do programa Visual Poços Pro (Schlumberger Water Services, 1998).

A caracterização estrutural foi realizada com base na interpretação de produtos de sensoriamento remoto (imagens de radar e fotografias aéreas) e de modelos digitais de elevação do terreno. Esses produtos foram utilizados na identificação dos lineamentos morfoestruturais existentes na região, sendo realizada a interpretação desses lineamentos visando identificar parâmetros como orientação e densidade. Também foram realizadas atividades de campo visando a identificação dos diferentes tipos de estruturas e suas características geométricas. A avaliação da existência de controle estrutural sobre os poços tubulares foi realizada através de mapeamento utilizando o programa ArGis 10.2 (ESRI, 2013).

Para composição do mapa de densidade de fraturas, utilizou-se o método de densidade de Kernel, disponível no referido programa. Para isso a região abrangida foi dividida em células 
com dimensões iguais de $10000 \mathrm{~m}^{2}$, onde foi contabilizado o número de fraturas que estavam inseridas em cada célula. Com isso foi possível gerar um mapa de densidade de fraturas contendo a delimitação de regiões com baixa (0-1 fratura), média ( 1 a 3 fraturas) e alta (acima de 3 fraturas).

A caracterização hidroquímica foi feita com base na interpretação dos resultados de análises físico-químicas realizadas em amostras de água subterrânea coletadas de poços tubulares. A seleção dos poços foi realizada com base nas informações geológicas, hidrogeológicas e construtivas disponíveis para os poços cadastrados, sendo que os poços selecionados deveriam captar água de aquíferos associados às rochas vulcânicas ácidas.

Assim, foram selecionados 12 poços tubulares pertencentes a Companhia Riograndense de Saneamento (CORSAN), onde foram realizadas duas coletas de amostras de água subterrânea nos meses de abril e julho de 2013. Para coleta, utilizou-se o sistema de bombeamento do poço, sendo a bomba acionada e mantida ligada, por pelo menos 10 minutos. Após esse tempo, realizou-se a coleta das amostras de água, na saída da tubulação ligada à bomba. Para cada ponto foram coletadas amostras e enviadas para análise laboratorial dos parâmetros ferro, bicarbonatos, manganês, fluoretos, alcalinidade, cloreto, sulfato, cálcio, magnésio, sódio e potássio. Parâmetros como $\mathrm{pH}$, condutividade e temperatura foram amostrados em campo, utilizando uma sonda multiparâmetros Horiba U50.

A avaliação dos relatórios analíticos foi feita com base na seleção dos parâmetros analisados e no erro cometido nas análises (Cálculo do Erro pelo Balanço Iônico). Os resultados das análises foram utilizados na montagem de um banco de dados e na elaboração de diagramas Piper (1944), Schoeller (1935) e Stiff (1951) com o uso do programa AcquaChem 5.1 (Schlumberger Water Services, 2008).

Como forma de auxiliar na determinação das relações entre as litologias constituintes dos aquíferos e o quimismo das águas subterrâneas, foram calculadas as razões iônicas ou índices hidrogeoquímicos (Hem, 1985), que podem indicar um relacionamento certo entre o litotipo e a água. As variações das razões iônicas de $\mathrm{Mg}^{+2} / \mathrm{Ca}^{+2}, \mathrm{~K}^{+} / \mathrm{Na}^{+}, \mathrm{Na}^{+} / \mathrm{Ca}^{+2}, \mathrm{Na}^{+} / \mathrm{Ca}^{+2}+\mathrm{Mg}^{+2}$, $\mathrm{HCO}_{3}{ }^{-} / \mathrm{Ca}^{+2}$ são indicativos da preponderância de determinado elemento sobre os outros elementos, em função, por exemplo, da composição mineralógica das rochas do sistema aquífero.

\section{RESULTADOS E DISCUSSÃO}

\subsection{Caracterização Hidrogeológica}

$\mathrm{Na}$ região de estudo há ocorrência de dois tipos principais de litologias: basaltos do tipo Gramado e vulcânicas ácidas do tipo Palmas/Caxias (Roisenberg e Viero, 2002). Com base nos levantamentos de campo pode-se identificar que em altitudes até 500 metros são encontradas rochas basálticas. Acima de 500 metros foram identificados 5 derrames de rochas ácidas, sendo os riolitos e o riodacitos os litotipos principais. Além disso, observou-se que os derrames ácidos apresentam disjunção horizontal e zonas vesiculares a amigdaloides. As amigdalas em geral, são preenchidas por quartzo e calcita.

A partir do levantamento de dados de fontes secundárias como SIAGAS e CORSAN foram identificados 137 poços perfurados no município de Carlos Barbosa. Desses 137 poços, 76 poços possuíam dados de nível estático, 57 de capacidade específica, 74 de vazão e 50 poços possuíam o número e a profundidade de entradas de água, os quais foram utilizados na caracterização hidrogeológica. Além disso, 12 poços localizados em rochas ácidas foram utilizados para coleta de amostras de água subterrânea a fim de realizar a caracterização hidroquímica (Figura 2). 


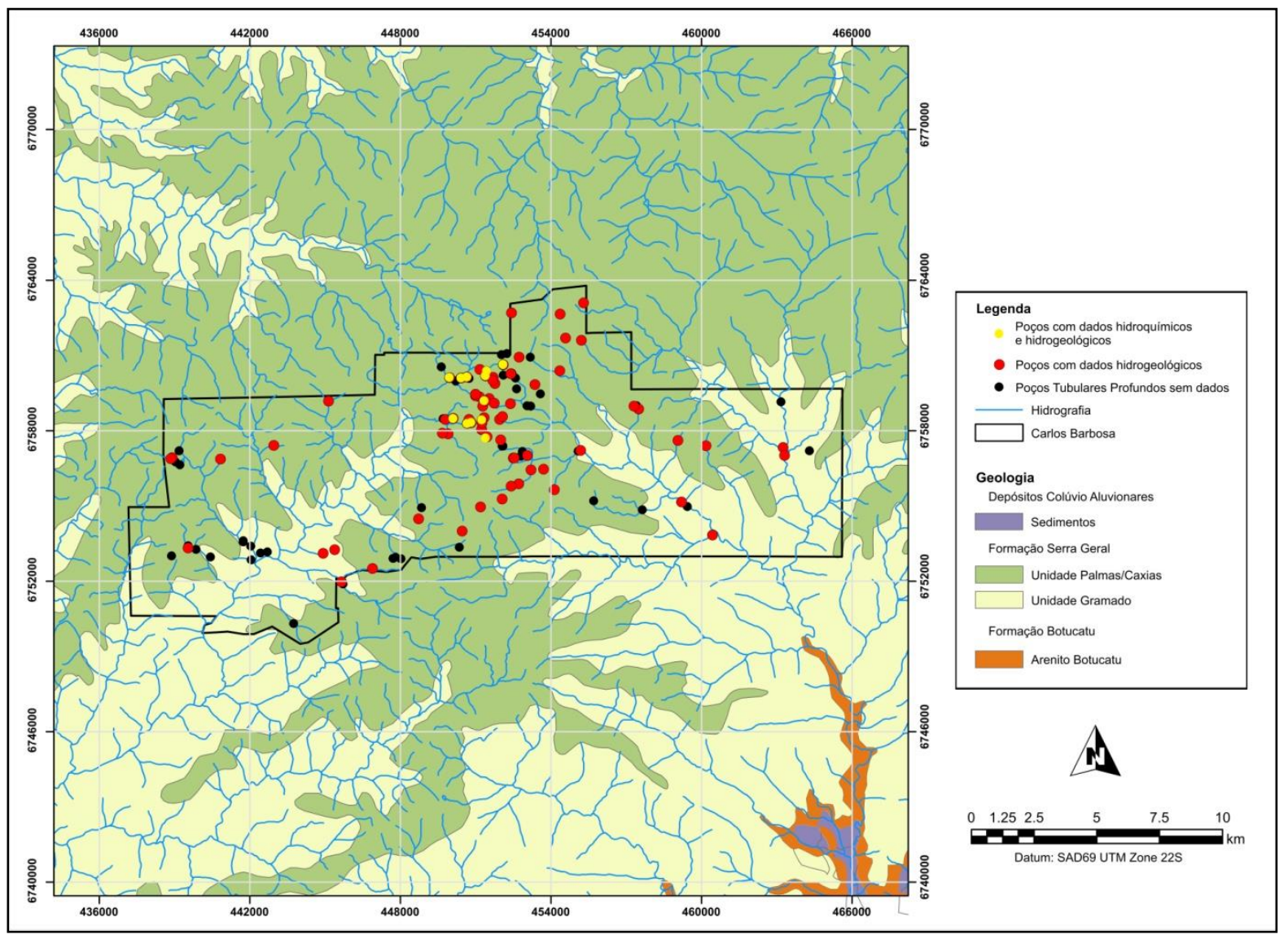

Figura 2. Localização dos poços de amostragem.

A análise hidrogeológica dos poços que possuíam dados (Tabela 1) permitiu identificar que, a maioria das captações tem profundidade entre 100 e 150 metros (39\%), seguida por profundidades entre 50 e 100 metros (34\%). Esses dados demonstram que os poços existentes na região, captam água de fraturas que estão localizadas no intervalo entre 50 e 150 metros.

Tabela 1. Distribuição percentual dos principais dados e parâmetros hidrodinâmicos obtidos da interpretação de dados dos poços tubulares.

\begin{tabular}{l|cccc}
\hline \multicolumn{1}{c|}{ Dados e Parâmetros } & \multicolumn{4}{c}{ Resultados } \\
\hline $\begin{array}{l}\text { Profundidade dos Poços (m) } \\
\text { Número de Entradas de Água }\end{array}$ & $1(36 \%)$ & $2(26 \%)$ & $3(18 \%)$ & $>3(20 \%)$ \\
\hline $\begin{array}{l}\text { Profundidade das Entradas de } \\
\text { Água }(\mathrm{m})\end{array}$ & 0 a $20(21 \%)$ & 20 a $50(26 \%)$ & 50 a $100(37 \%)$ & $>100(16 \%)$ \\
$\begin{array}{l}\text { Nível Estático }(\mathrm{m}) \\
\begin{array}{l}\text { Capacidade Específica } \\
\left(\mathrm{q}-\mathrm{m}^{3} / \mathrm{h} / \mathrm{m}\right)\end{array}\end{array}$ & 0 a $5(41 \%)$ & 5 a $10(18 \%)$ & 10 a $20(14 \%)$ & $>20(26 \%)$ \\
$\begin{array}{l}\text { Transmissividade }\left(\mathrm{m}^{2} / \mathrm{h}\right) \\
\text { a } 0,3(42 \%)\end{array}$ & 0,3 a $0,5(19 \%)$ & 0,5 a $1,0(23 \%)$ & $>1,0(16 \%)$ \\
\begin{tabular}{l} 
Vazão $\left(\mathrm{m}^{3} / \mathrm{h}\right)$ \\
\hline
\end{tabular} & 0 a $5(26 \%)$ & 5 a $10(22 \%)$ & 10 a $20(32 \%)$ & $>20(20 \%)$ \\
\hline
\end{tabular}


Identificou-se também que a maior parte dos poços possui de 1 a 3 entradas de água (80\%), localizadas entorno de 50 a 100 metros de profundidade (37\%). Alguns poços possuem entradas até 20 metros $(21 \%)$ e $26 \%$ dos poços possuem entradas de água entre 20 e 50 metros.

O nível estático (NE) está associado a diferentes profundidades, sendo na maior parte dos casos, localizado entre 0 e 5 metros de profundidade (41\%). Isso evidencia que o aquífero fraturado, embora tenha entradas de água localizadas em diferentes níveis, possui um comportamento semelhante a aquíferos confinados ou semi-confinados. Dessa forma, a água subterrânea presente no aquífero, encontra-se sob pressão e, após a perfuração, tende a subir além da entrada de água.

Os cálculos hidrogeológicos com as informações dos testes de vazão de poços confirmam a baixa transmissividade, na maioria das vezes, muito baixas, sendo que a maioria dos poços apresentam valores no intervalo entre 0,1 e $0,5 \mathrm{~m}^{2} \mathrm{~h}^{-1}$, seguido por valores de até $0,1 \mathrm{~m}^{2} \mathrm{~h}^{-1}$ (42\%), variação típica de aquíferos fraturados (anisotrópicos).

A capacidade específica analisada indicou grande variação, ocorrendo na maior parte dos casos valores que estão no intervalo de 0 e $0,3 \mathrm{~m}^{3} / \mathrm{h} / \mathrm{m}(42 \%)$, seguidos por valores entre 0,5 a $1 \mathrm{~m}^{3} / \mathrm{h} / \mathrm{m}(23 \%)$ e por valores entre 0,3 a $0,5 \mathrm{~m}^{3} / \mathrm{h} / \mathrm{m}(19 \%)$, variabilidade condizente com o tipo de aquífero (fraturado), que por sua vez apresenta uma forte anisotropia.

Outro parâmetro analisado correspondeu à vazão, que apresentou na maioria dos poços analisados um valor entre 10 a $20 \mathrm{~m}^{3} \mathrm{~h}^{-1}(32 \%)$, seguida por uma vazão inferior a $5 \mathrm{~m}^{3} \mathrm{~h}^{-1}$ (26\%). Dependendo da localização do poço em relação ao lineamento, bem como da orientação do lineamento (nordeste ou noroeste), haverá diferenças significativas na vazão. Além disso, fatores relacionados com o projeto e a perfuração dos poços como profundidade, diâmetro, captação de outros aquíferos como o Sistema Aquífero Guarani, bem como o número de entradas de água, também têm influência na vazão.

$\mathrm{Na}$ região, foram identificados 266 lineamentos, sendo em sua maioria de pequeno porte (até $10 \mathrm{~km}$ ) com orientação preferencial para noroeste (N0-10W; N20-30W; N40-50W e N60-70W) e a secundária, para nordeste (N30-50E), como mostra a Figura 3. A maioria dos poços encontra-se em zona de média a alta densidade de fraturas, região mais propícia a ser encontrado um volume maior de água.

O cruzamento dos dados dos poços tubulares com as estruturas permitiu identificar a existência de um controle estrutural que têm influência na capacidade específica e produção desses poços. Assim, poços que estão associados a lineamentos de orientação noroeste e, em regiões com mais alta densidade de lineamentos são os poços mais produtivos.

\subsection{Caracterização Hidroquímica}

As características físico-químicas das águas subterrâneas do Sistema Aquífero Serra Geral (SASG) possuem variações condicionadas pelas características geológicas e hidrogeológicas da região, o que pode ser evidenciada através da caracterização hidroquímica (Reginato e Strieder, 2004). A circulação das águas subterrâneas nesses aquíferos é condicionada pelo sistema de fraturas e pelas estruturas de resfriamento dos derrames de rochas vulcânicas. Assim, as águas circulam em diferentes níveis de profundidade, em diferentes condições de confinamento e podem apresentar características hidroquímicas variadas.

A classificação das águas subterrâneas das duas amostragens realizadas, com base no Diagrama de Piper (Figura 4), indicou a ocorrência de um único campo que é o das águas bicarbonatadas cálcicas ou magnesianas.

Pela análise dos cátions observa-se que essas águas são cálcicas ou mistas. A ocorrência desse tipo de água está de acordo com os estudos do sistema aquífero Serra Geral realizados por Mobus (1987), Fraga (1992), Hausman (1966; 1995), Bittencourt (2003), Machado e 
Freitas (2005) e estudos regionais realizados por Lisboa (1996), Betiollo (2006), Nanni (2008) e Reginato et al. (2013), sendo que a fonte dos elementos cálcio, magnésio e sódio está relacionada com os silicatos presentes nas diferentes rochas vulcânicas. Conforme Lisboa (1996) as águas que circulam no SASG tendem a apresentar uma relação onde o $\mathrm{Ca}>\mathrm{Mg}>\mathrm{Na}$ predomina e um enriquecimento de cálcio e magnésio do topo (rochas ácidas) para a base (rochas básicas).

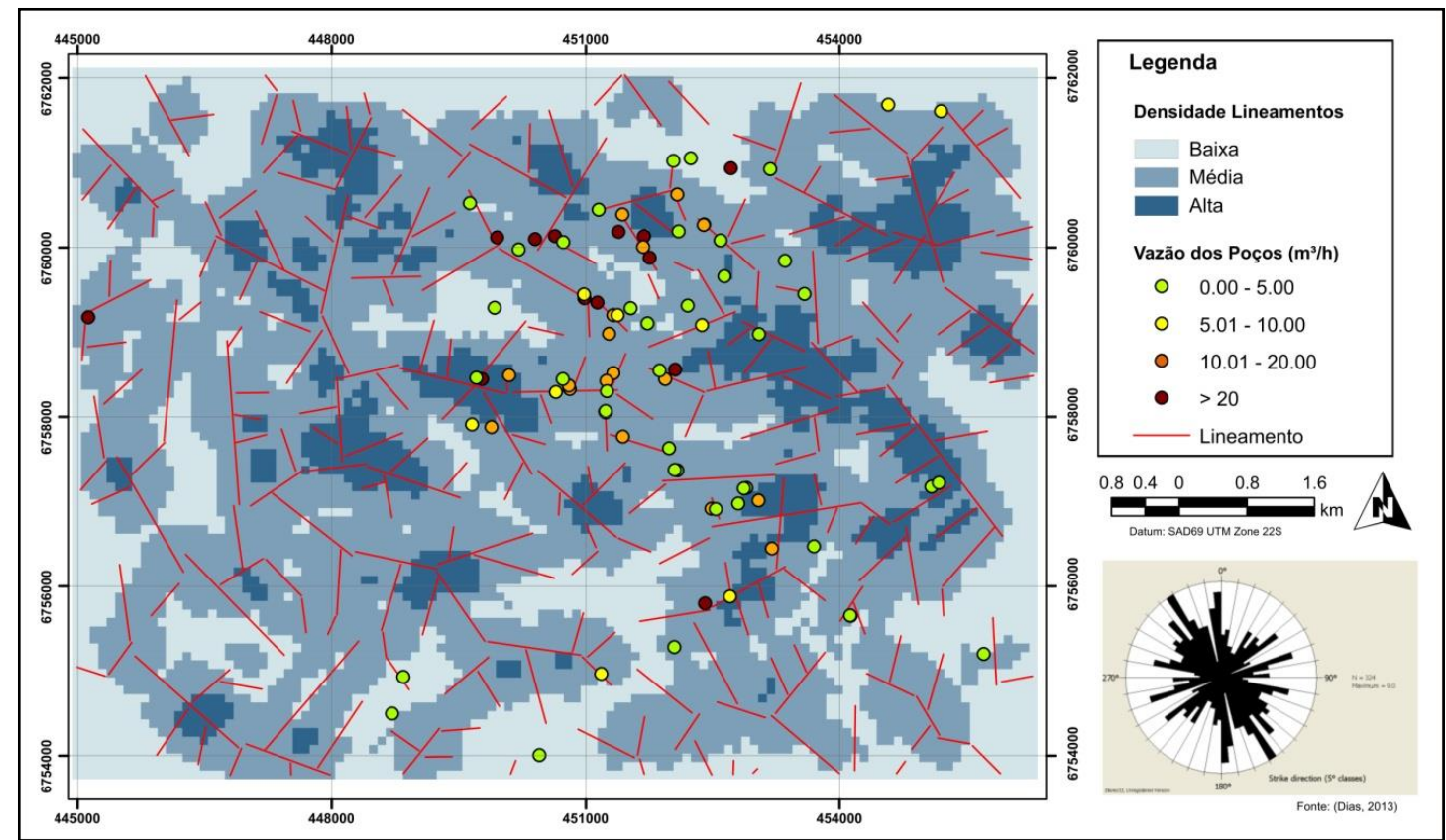

Figura 3. Mapa de densidade de fraturas e diagrama de roseta com as direções dos lineamentos.

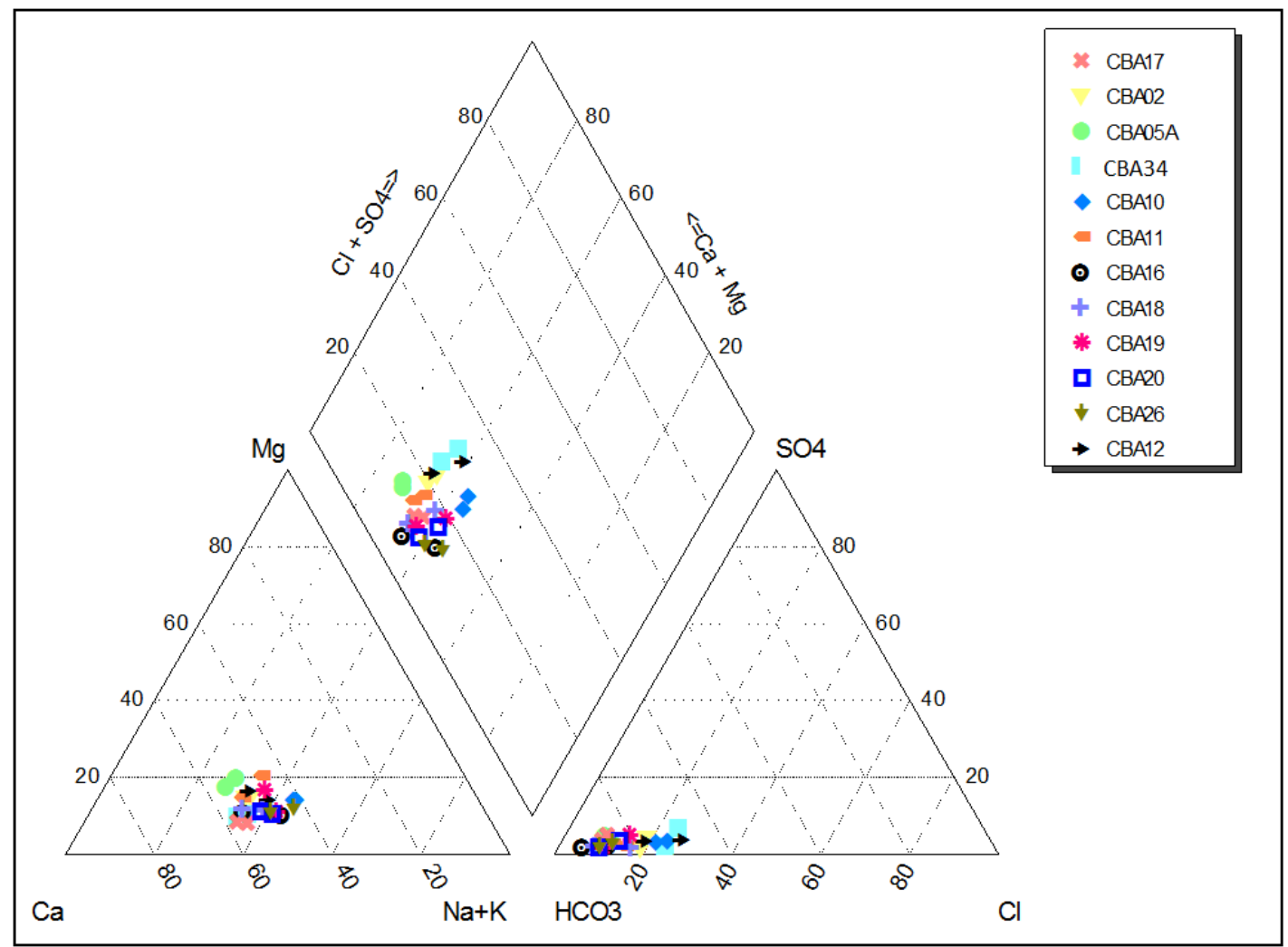

Figura 4. Diagrama Piper das amostras de água subterrânea do SASG. 
As águas bicarbonatadas cálcicas ou magnesianas analisadas apresentaram os resultados médios entre as duas campanhas realizadas apresentados na Tabela 2.

Tabela 2. Valores médios dos parâmetros analisados das duas amostragens realizadas.

\begin{tabular}{|c|c|c|c|c|c|c|c|c|c|c|c|c|}
\hline Poço & CBA02 & CBA05A & CBA10 & CBA11 & CBA12 & CBA16 & CBA17 & CBA18 & CBA19 & CBA20 & CBA26 & CBA34 \\
\hline Temp $\left({ }^{\circ} \mathrm{C}\right)$ & 17,84 & 18,14 & 17,80 & 17,85 & 17,91 & 18,41 & 18,28 & 18,01 & 18,10 & 17,69 & 17,56 & 17,72 \\
\hline $\mathrm{pH}$ & 6,23 & 6,07 & 5,52 & 5,73 & 5,80 & 6,19 & 6,18 & 6,04 & 6,08 & 6,13 & 6,17 & 6,22 \\
\hline Cond. (uS cm $\left.{ }^{-1}\right)$ & 196,00 & 159,00 & 108,50 & 141,50 & 110,50 & 145,50 & 189,00 & 148,50 & 150,00 & 141,50 & 102,50 & 168,50 \\
\hline Alctotal (mg L $\left.{ }^{-1}\right)$ & 60,64 & 61,40 & 25,57 & 39,84 & 24,59 & 60,88 & 77,15 & 54,62 & 56,35 & 57,35 & 41,51 & 46,11 \\
\hline $\mathrm{HCO} 3\left(\mathrm{mg} \mathrm{L}^{-1}\right)$ & 74,42 & 74,55 & 31,12 & 50,65 & 29,87 & 74,10 & 94,40 & 66,31 & 69,25 & 70,00 & 49,73 & 56,13 \\
\hline $\mathrm{Ca}^{+2}\left(\mathrm{mg} \mathrm{L}^{-1}\right)$ & 20,63 & 17,38 & 8,69 & 11,69 & 9,46 & 15,45 & 21,90 & 14,95 & 14,64 & 14,89 & 9,96 & 17,71 \\
\hline $\mathrm{Cl}^{-}\left(\mathrm{mg} \mathrm{L}^{-1}\right)$ & 10,33 & 5,15 & 5,41 & 4,75 & 5,34 & 3,98 & 5,85 & 5,64 & 5,73 & 5,09 & 3,36 & 11,11 \\
\hline $\mathrm{F}^{-}\left(\mathrm{mg} \mathrm{L}^{-1}\right)$ & 0,51 & 0,56 & 0,86 & 0,54 & 0,49 & 0,95 & 0,85 & 0,59 & 0,37 & 0,70 & 0,90 & 0,54 \\
\hline $\mathrm{Fe}^{+2}\left(\mathrm{mg} \mathrm{L}^{-1}\right)$ & 0,06 & 0,06 & 0,06 & 0,06 & 0,06 & 0,07 & 0,06 & 0,06 & 0,06 & 0,06 & 0,06 & 0,06 \\
\hline $\mathrm{Mg}^{+2}\left(\mathrm{mg} \mathrm{L}^{-1}\right)$ & 3,55 & 3,58 & 1,74 & 2,54 & 1,76 & 1,88 & 1,86 & 1,96 & 2,55 & 1,90 & 1,48 & 1,92 \\
\hline $\mathrm{Mn}^{+2}\left(\mathrm{mg} \mathrm{L}^{-1}\right)$ & 0,04 & 0,04 & 0,04 & 0,04 & 0,04 & 0,18 & 0,04 & 0,04 & 0,04 & 0,04 & 0,04 & 0,04 \\
\hline $\mathrm{K}^{+}\left(\mathrm{mg} \mathrm{L}^{-1}\right)$ & 4,54 & 1,01 & 5,32 & 3,33 & 3,25 & 2,65 & 1,09 & 2,13 & 3,94 & 2,22 & 1,96 & 2,74 \\
\hline $\mathrm{Na}^{+}\left(\mathrm{mg} \mathrm{L}^{-1}\right)$ & 12,89 & 9,72 & 7,39 & 7,09 & 6,09 & 12,11 & 15,32 & 10,77 & 11,55 & 12,36 & 9,45 & 11,18 \\
\hline $\mathrm{SO}_{4}^{-2}\left(\mathrm{mg} \mathrm{L}^{-1}\right)$ & 2,00 & 2,50 & 1,00 & 1,00 & 1,00 & 1,00 & 3,50 & 1,00 & 2,00 & 1,50 & 1,00 & 2,50 \\
\hline $\operatorname{STD}\left(\mathrm{mg} \mathrm{L}^{-1}\right)$ & 127,50 & 131,50 & 70,50 & 77,50 & 72,00 & 94,50 & 123,00 & 98,50 & 97,50 & 92,00 & 67,00 & 109,50 \\
\hline
\end{tabular}

Em geral as águas do aquífero Serra Geral apresentam concentrações variáveis de cálcio, magnésio e sódio e, pequenas concentrações de cloretos e sulfatos. A concentração média de Cálcio de $14,78 \mathrm{mg} \mathrm{L}^{-1}$ está diretamente relacionada ao arcabouço químico-mineralógico do aquífero, pois reflete a remoção do cálcio dos plagioclásios e minerais ferromagnesianos dos basaltos. A solubilidade do $\mathrm{Ca}^{2+} \mathrm{em}$ águas naturais está vinculada à presença de espécies carbônicas dissolvidas como $\mathrm{H}_{2} \mathrm{CO}_{3}, \mathrm{HCO}_{3}$ e $\mathrm{CO}_{3}{ }^{2}$ (Mocelin e Ferreira, 2009).

A concentração de carbonatos e bicarbonatos são baixas, quando comparados por exemplo às águas do Sistema Aquífero Guarani. As águas Bicarbonatadas Cálcicas ou Magnesianas apresentam $\mathrm{pH}$ que varia de 5,5 a 6,3, sólidos totais dissolvidos (STD) de 70,5 a $131,5 \mathrm{mg} \mathrm{L}^{-1}, \mathrm{Na}^{+2}$ de 6,09 a $15,32 \mathrm{mg} \mathrm{L}^{-1}$, valores baixos, devido principalmente às entradas de água estarem associadas aos derrames de rochas vulcânicas ácidas. A dureza varia de 24 a $77 \mathrm{mg} \mathrm{L}{ }^{-1}$ de $\mathrm{CaCO}_{3}$, com média de $70,6 \mathrm{mg} \mathrm{L}^{-1}$, o que caracteriza tais águas como pouco duras. Tais valores representam características de águas com pouco tempo de residência com recarga relacionada às precipitações pluviométricas através do manto de intemperismo (Hausmann, 1966; Lisboa, 1996).

Foram encontradas concentrações baixas de fluoreto que variam entre 0,37 e $0,95 \mathrm{mg} \mathrm{L}^{-1}$, valores que podem estar relacionados a mineralizações presentes nas fraturas. Nanni (2008) sugere que o enriquecimento de fluoreto no SASG decorre da combinação de recarga 
ascendente do Sistema Aquífero Guarani (SAG) em condições de alto confinamento e longo tempo de residência, situação não encontrada na região de estudo, uma vez que não há evidências de conexão com o SAG.

O ferro, comum nos óxidos de ferro (hematita e magnetita) e manganês que está intimamente associado com o ferro, apresentaram concentrações inferiores a $0,07 \mathrm{mg} \mathrm{L}^{-1} \mathrm{e}$ $0,32 \mathrm{mg} \mathrm{L}^{-1}$, respectivamente. As reduzidas concentrações de cloreto encontradas, em geral inferiores a $6 \mathrm{mg} \mathrm{L}^{-1}$, com exceção dos poços CBA02 e CBA34, que possuem concentrações superiores a $10 \mathrm{mg} \mathrm{L}^{-1}$, são explicadas devido às rochas ígneas serem pobres em cloretos.

A Figura 5 apresenta os diagramas de Stiff para algumas amostras realizadas, os quais mostram uma figura geométrica característica para a água analisada.

CBA17,30/04/2013

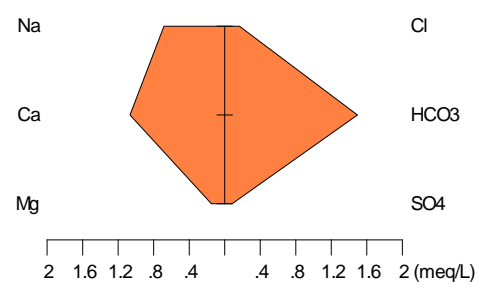

CBA12,24/07/2013

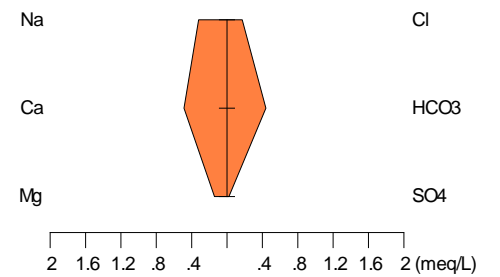

CBA10,24/07/2013

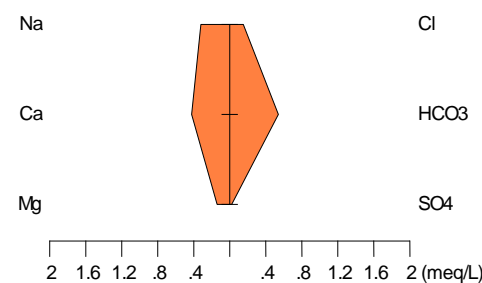

CBA11,30/04/2013

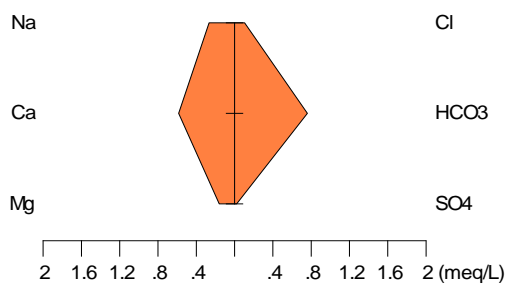

CBA05A,24/07/2013

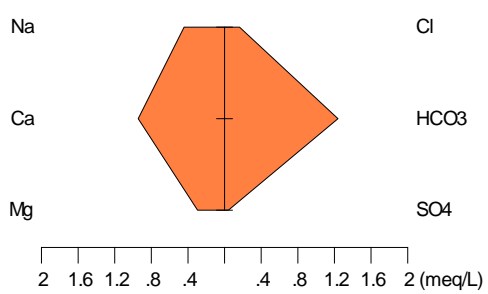

Figura 5. Geometrias observadas no Diagrama de Stiff das amostras de água subterrânea do SASG na área de estudo.

As amostras apresentam uma feição geométrica semelhante, com variação apenas na concentração dos íons. Os poços que apresentam maior concentração de cálcio também possuem maior concentração de carbonatos indicando um maior grau de dissolução da calcita, resultado de maior tempo de armazenamento no aquífero e maiores profundidades de armazenamento. Um exemplo desse comportamento é o poço CBA17, o qual possui entrada d'água localizada aos 101 metros.

A análise do diagrama de Schoeller (Figura 6) indica a existência de um comportamento hidroquímico geral com pequenas variações nas concentrações dos íons analisados. As variações mais significativas estão relacionadas às concentrações de magnésio, sódio, cloro e sulfato e podem ser explicadas pela ocorrência de diferentes entradas de água, localizadas em profundidades distintas de diferentes derrames de rochas vulcânicas ácidas. 


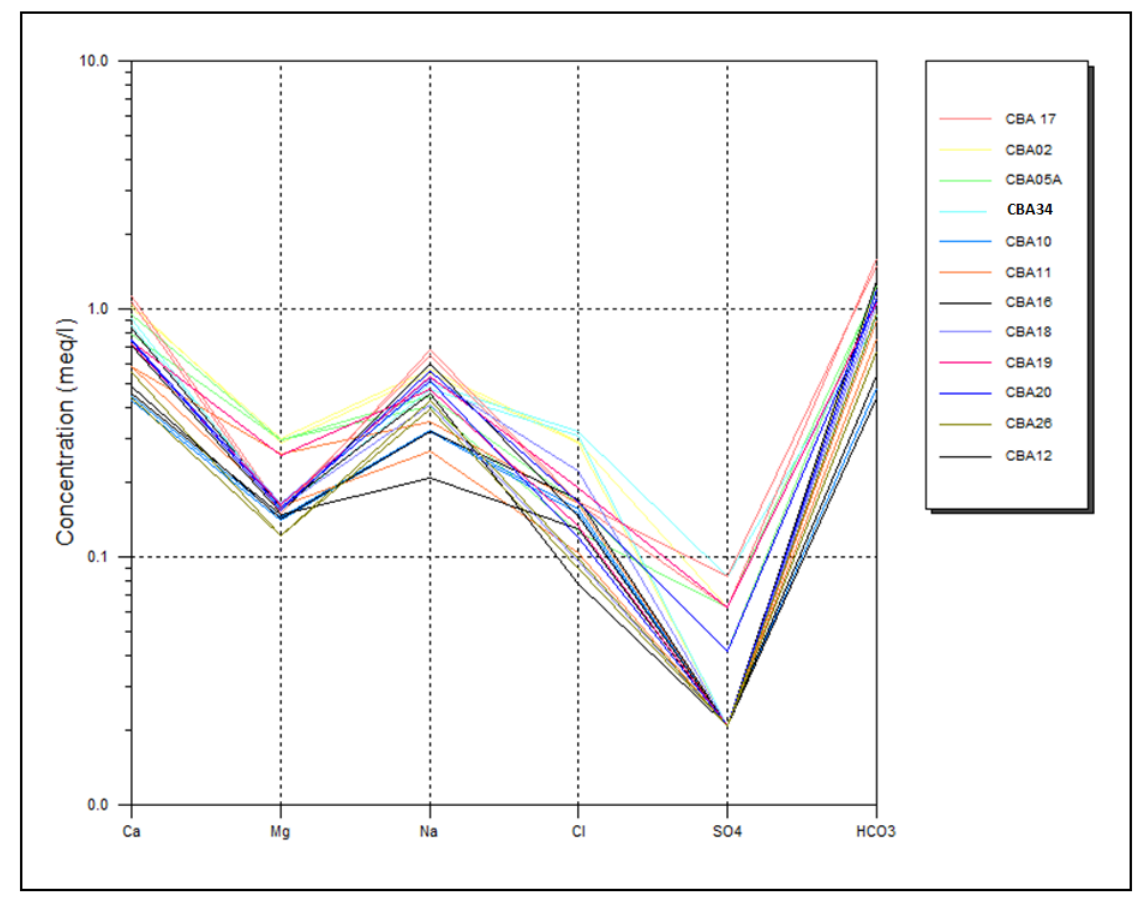

Figura 6. Diagrama de Schoeller das amostras de água subterrânea do SASG na área de estudo.

A diferença na concentração dos íons também dependem do volume da água do aquífero, tipo de ambiente geológico e formas de ocupação, características hidrogeológicas das camadas ou corpos aquíferos, características inerentes a água ( $\mathrm{pH}$, solubilidade, agressividade, entre outros), reações químicas e biológicas que acontecem dentro do próprio sistema de fluxo subterrâneo e características climáticas como pluviometria, evaporação, evapotranspiração e variação da temperatura (Feitosa, 2008).

$\mathrm{O}$ uso de relações entre diversos íons podem fornecer o tipo de reações químicas que estão associados aos processos hidroquímicos. A Tabela 3 apresenta a média dos valores encontradas das razões iônicas para as duas amostragem realizadas.

Tabela 3. Razões iônicas em meq $\mathrm{L}^{-1}$.

\begin{tabular}{c|ccccccccc}
\hline Poço & $\mathbf{r M g}^{+2} / \mathbf{C a}^{+2}$ & $\mathbf{r K}^{+} / \mathbf{N a}^{+}$ & $\mathbf{r N a}^{+} / \mathbf{C a}^{+2}$ & $\mathbf{r N a}^{+} / \mathbf{C a}^{+2}+\mathbf{M g}^{+2}$ & $\mathbf{r C l} / \mathbf{H C O}_{3}$ & $\mathbf{r N a} / \mathbf{C l}$ & $\mathbf{r H C O}{ }^{-} / \mathbf{C a}^{+2}$ & $\mathbf{r C a}^{+2} / \mathbf{M g}^{+2}$ & $\mathbf{r N a}^{+} / \mathbf{K}^{+}$ \\
\hline CBA02 & 0,284 & 0,207 & 0,545 & 0,424 & 0,239 & 1,924 & 1,185 & 3,527 & 4,828 \\
\hline CBA05A & 0,342 & 0,061 & 0,489 & 0,364 & 0,119 & 2,941 & 1,418 & 2,946 & 16,623 \\
\hline CBA10 & 0,329 & 0,423 & 0,742 & 0,558 & 0,301 & 2,107 & 1,178 & 3,038 & 2,365 \\
\hline CBA11 & 0,359 & 0,284 & 0,529 & 0,387 & 0,159 & 2,348 & 1,424 & 2,949 & 3,656 \\
\hline CBA12 & 0,307 & 0,334 & 0,558 & 0,428 & 0,315 & 1,741 & 1,041 & 3,265 & 3,261 \\
\hline CBA16 & 0,201 & 0,130 & 0,694 & 0,577 & 0,095 & 4,981 & 1,576 & 4,989 & 7,752 \\
\hline CBA17 & 0,140 & 0,042 & 0,611 & 0,536 & 0,107 & 4,041 & 1,416 & 7,138 & 23,901 \\
\hline CBA18 & 0,216 & 0,119 & 0,628 & 0,516 & 0,145 & 3,325 & 1,457 & 4,634 & 8,739 \\
\hline CBA19 & 0,286 & 0,201 & 0,688 & 0,539 & 0,144 & 3,172 & 1,552 & 3,670 & 4,988 \\
\hline CBA20 & 0,210 & 0,105 & 0,724 & 0,598 & 0,126 & 3,810 & 1,543 & 4,753 & 9,482 \\
\hline CBA26 & 0,247 & 0,124 & 0,834 & 0,668 & 0,119 & 4,342 & 1,629 & 4,092 & 9,485 \\
\hline CBA34 & 0,179 & 0,144 & 0,551 & 0,467 & 0,341 & 1,551 & 1,041 & 5,604 & 6,952 \\
\hline Média & $\mathbf{0 , 2 5 8}$ & $\mathbf{0 , 1 8 1}$ & $\mathbf{0 , 6 3 3}$ & $\mathbf{0 , 5 0 5}$ & $\mathbf{0 , 1 8 4}$ & $\mathbf{3 , 0 2 4}$ & $\mathbf{1 , 3 7 2}$ & $\mathbf{4 , 2 1 7}$ & $\mathbf{8 , 5 0 3}$ \\
\hline
\end{tabular}

As razões iônicas calculadas permitem evidenciar fluxo de água por rochas vulcânicas, observadas pela razão $\mathrm{rNa}^{+} / \mathrm{Cl}^{-}$maior que 0,7 como apresentado por Hem (1985) e pela 
relação $\mathrm{rNa}^{+} / \mathrm{Ca}^{+2}$ ser inferior a 1 , corroborando com a caracterização do diagrama Piper em águas bicarbonatadas cálcicas, valor também apontado por Portela Filho et al. (2005) no estudo da contribuição do aquífero basáltico sobrejacente ao Sistema Aquífero Guarani. A origem do bicarbonato é oriunda da dissolução da calcita, a qual apresenta uma razão teórica $\mathrm{rHCO}_{3} / \mathrm{Ca}^{+2}$ próxima de 1,5 (Roisenberg et al., 2003), sendo encontrado em média nos poços analisados um valor próximo a 1,4.

Outras razões iônicas como $\mathrm{rMg}^{+2} / \mathrm{Ca}^{+2}, \mathrm{rK}^{+} / \mathrm{Na}^{+} \mathrm{e} \mathrm{rNa}^{+} / \mathrm{Ca}^{+2}$ foram encontradas em média e respectivamente no valor de $0,258,0,181$ e 0,633 , valores que estão dentro dos intervalos atribuídos em outros estudos da Formação Serra Geral como de Gastmans et al. (2005). A razão $\mathrm{rNa}^{+} / \mathrm{K}^{+}$maior que 1 e mais elevada nos poços CBA05A e CBA17, é indicativa de um fluxo com maior tempo de permanência. Segundo Bittencourt et al. (2003), valores mais elevados da relação $\mathrm{rNa}^{+} / \mathrm{K}^{+}$são indicativos de fluxo em basaltos. Embora os poços tubulares selecionados, foram perfurados na sequência de rochas vulcânicas ácidas, as estruturas tectônicas encontradas nas litologias cortam diferentes derrames e podem proporcionar diferentes padrões de circulação, dando origem a padrões hidroquímicos e razões iônicas distintas.

\section{CONCLUSÕES}

$\mathrm{Na}$ região abrangida pelo município de Carlos Barbosa há ocorrência de aquíferos fraturados que fazem parte do Sistema Aquífero Serra Geral e que estão localizados nos derrames de rochas ácidas da Formação Serra Geral. A maioria das captações possuem profundidades entre 50 e 150 metros, nível estático localizado entre 0 e 5 metros, capacidade específica entre 0 e $0,3 \mathrm{~m} / \mathrm{h} / \mathrm{m}$ e vazão que varia entre 5 a $20 \mathrm{~m}^{3} \mathrm{~h}^{-1}$. O maior percentual de poços possui entre 1 a 3 entradas da água, localizadas em torno de 50 a 100 metros de profundidade e em zonas de média e alta densidade de fraturas, as quais possuem orientação preferencial de noroeste.

As águas subterrâneas que circulam por esses aquíferos são do tipo bicarbonatadas cálcicas ou magnesianas, predominando as águas bicarbonatadas mistas e cálcicas. A análise dos diagramas como Schoeller e Stiff indica a existência de um comportamento hidroquímico geral com pequenas variações nas concentrações dos íons analisados. Além disso, as razões iônicas encontradas são características da região de fluxo de água associado a rochas vulcânicas. Por fim a caracterização hidroquímica indica que as águas subterrâneas dessa região apresentam baixo grau de mineralização e baixo tempo de residência, sendo que as exceções foram encontradas em poços que possuíam entradas de água mais profundas.

\section{AGRADECIMENTOS}

Os autores agradecem ao Programa de Pós-Graduação em Recursos Hídricos e Saneamento Ambiental (IPH/UFRGS) e à Companhia Riograndense de Abastecimento (CORSAN) pela execução desta pesquisa e à FINEP, à Universidade de Brasília (UnB), ao Instituto de Saneamento Ambiental da Universidade de Caxias do Sul (ISAM/UCS) pelo financiamento do projeto.

\section{REFERÊNCIAS}

BETIOLLO, L. M. Caracterização estrutural, hidrogeológica e hidroquímica dos sistemas aquíferos Guarani e Serra Geral no nordeste do Rio Grande do Sul, Brasil. 2006. Dissertação (Mestrado em Geociências) - Instituto de Geociências. Programa de Pós-Graduação em Geociências, Universidade Federal do Rio Grande do Sul, Porto Alegre, 2006. 
BITTENCOURT, A. V. L.; ROSA FILHO E. F.; HINDI, E. C.; BUCHMANN FILHO, A. C. A influência dos basaltos e de misturas com águas de aquíferos sotopostos nas águas subterrâneas do Sistema Aquífero Serra Geral na bacia do rio Piquiri, Paraná - BR. Revista Águas Subterrâneas, v. 17, p. 67-76, 2003.

ESRI. ArcGis for Desktop 10.2. Redlands, 2013.

FEITOSA, F. A. C. Hidrogeologia: conceitos e aplicações. 3. ed., rev. e ampl. Rio de Janeiro: CPRM; LABHID, 2008. 812p.

FRAGA, C. G. Origem de fluoreto em águas subterrâneas dos sistemas aquíferos Botucatu e Serra Geral da Bacia do Paraná. 1992. 178p. Tese (Doutorado) - Instituto de Geociências, Universidade de São Paulo, São Paulo, 1992.

GASTMANS, D.; ALBERTO, M. C.; BUFFON, A. G. M.; MORAES, F. T.; SANTOS, M. M.; SILVA, J. R. M.; et al. Implicações hidroquímicas da interação rocha-água: interpretações através da representação gráfica de análises químicas de águas subterrâneas. In: ENCONTRO NACIONAL DE PERFURADORES DE POÇOS, 14.; SIMPÓSIO DE HIDROGEOLOGIA DO SUDESTE, 2., 2005, Ribeirão Preto. Anais... Ribeirão Preto: ABAS, 2005.

HAUSMAN, A. Comportamento do freático nas áreas basálticas do Rio Grande do Sul. Boletim Paranense de Geografia, v. 20, n. 18, p. 177-215, 1966.

HAUSMAN, A. Províncias hidrogeológicas do estado do Rio Grande do Sul, RS. Estudos

Tecnológicos: Acta Geológica Leopoldensia, Série Mapas, n. 2, p. 1-127, 1995.

HEM, L. D. Study and interpretation of the checimical characteristics of natural water. 3. edi. Washington: United States Government Printing Office, 1985. (U.S Geological Survey Water-Supply Paper, 2254).

LISBOA, N. A. Fácies, estratificações hidrogeoquímicas e seus controladores geológicos, em unidades hidrogeológicas do sistema aquífero Serra Geral, na bacia do Paraná, Rio Grande do Sul. 1996. 135p. Tese (Doutorado em Geociências) - Instituto de Geociências, Programa de Pós-Graduação em Geociências, Universidade Federal do Rio Grande do Sul, 1996.

MACHADO, J. L. F.; FREITAS, M. A. de. Projeto mapa hidrogeológico do Rio Grande do Sul: relatório final. Porto Alegre: CPRM, 2005. 65p. il. 1 mapa.

MOCELIN, R. C.; FERREIRA, F. J. F. Conectividade e compartimentação dos sistemas aquíferos Serra Geral e Guarani no sudoeste do estado do Paraná, Brasil. Revista Brasileira de Geociências, São Paulo, v. 39, n. 3, 2009.

MOBÜS, G. Analise estrutural e hidrogeológica do aquífero fraturado da Formação Serra Geral-Região noroeste do Rio Grande do Sul. 1987. 124p. Dissertação (Mestrado em Recursos Hídricos e Saneamento Ambiental) - Instituto de Pesquisas Hidráulicas, Universidade Federal do Rio Grande do Sul, Porto Alegre, 1987.

NANNI, A. S. O flúor em águas do Sistema Aquífero Serra Geral no Rio Grande do Sul: origem e condicionamento geológico. 2008. 127p. Tese (Doutorado em Geociências). Instituto de Geociências, Universidade Federal do Rio Grande do Sul, Porto Alegre, 2008 . 
PIPER A. M. A graphic procedure in the geochemical interpretation of water-analyses. Transactions of the American Geophysical Union, v. 25, p. 914-928, 1944.

PORTELA FILHO C. V.; FERREIRA F. J. F.; ROSA FILHO, E. F.; ROSTIROLLA S. P. Compartimentação magnética-estrutural do Sistema Aquífero Serra Geral e sua conectividade com o Sistema Aquífero Guarani na região central do arco de Ponta Grossa (Bacia do Paraná). Revista Brasileira de Geociências, São Paulo, v. 35, n. 3, p. 369-381, 2005.

REGINATO, P. A. R. Integração de dados geológicos para prospecção de aquíferos fraturados em trecho da Bacia Hidrográfica Taquari-Antas (RS). 2003. 254p. Tese (Doutorado em Engenharia) - Escola de Engenharia, Programa de Pós-Graduação em Engenharia de Minas, Metalúrgica e dos Materiais, Universidade Federal do Rio Grande do Sul, Porto Alegre, 2003.

REGINATO, P. A. R.; AHLERT, S.; GILIOLI, K. C.; CEMIN, G. Caracterização hidrogeológica e hidroquímica do aquífero livre do manto de alteração da Formação Serra Geral, na bacia hidrográfica Taquari-Antas, região nordeste do estado do Rio Grande do Sul. Revista Ambi-Agua, Taubaté, v. 7, n. 1, 2012. http://dx.doi.org/10.4136/ambi-agua.903

REGINATO, P. A. R. ; STRIEDER, A. J. Caracterização hidrogeológica e potencialidades dos aqüíferos fraturados da Formação Serra Geral na região nordeste do Estado do Rio Grande do Sul. In: CONGRESSO BRASILEIRO DE ÁGUAS SUBTERRÂNEAS, 13., 2004, Cuiabá. Anais... São Paulo: ABAS, 2004. v.1.

REGINATO, P. A. R.; AHLERT S.; SCHNEIDER, V. E. Caracterização hidroquímica do sistema aquífero Serra Geral na região nordeste do Rio Grande do Sul. Águas Subterrâneas, v. 27, n. 1, p. 65-78, 2013.

ROISENBERG, A.; VIERO, A. P. O vulcanismo mesozoico da Bacia do Paraná no Rio Grande do Sul. In: HOLZ, M.; DE ROS, L. F. Geologia do Rio Grande do Sul. Porto Alegre: CIGO/UFRGS. 2000.

ROISENBERG, C.; VIERO, A. P.; ROISENBERG, A.; SCHWARZBACH, M. S. R., MORANTE, I. C. Caracterização geoquímica e gênese dos principais íons das águas Subterrâneas de Porto Alegre, RS. Revista Brasileira de Recursos Hídricos, v. 8, n. 4, p. 137-147, out./dez. 2003.

SCHLUMBERGER WATER SERVICES. Software Visual Poços Pro. Reno, 1998.

SCHLUMBERGER WATER SERVICES. Software AcquaChem 5.1. Reno, 2008.

SCHOELLER, H. Utilité de la notion des exchanges de bases pour la comparasion des eaux souterraines. Société Géologie Comptes Rendus Sommaire et Bulletin, série 5, n. 5, p. 651-657, 1935.

STIFF, H. A. The interpretation of chemical water analysis by means of paterns. Journal of Petroleoum Technology, v. 3, n. 10, p. 15-17, 1951. http://dx.doi.org/10.2118/951376-G 